\title{
Mapping of Freshwater Snails' Habitat-A Source of Transmitting Bilharzia in Mwea Sub-County, Kenya
}

\author{
Mark Kipkurwa Boitt1 ${ }^{*}$, Mungai Kaara Suleiman² \\ ${ }^{1}$ Institute of Geomatics, GIS and Remote Sensing, Dedan Kimathi University of Technology, Nyeri, Kenya \\ ${ }^{2}$ Department of Geomatic Engineering and GIS, Jomo Kenyatta University of Agriculture and Technology, Nairobi, Kenya \\ Email: ^mark.boitt@dkut.ac.ke
}

How to cite this paper: Boitt, M. K., \& Suleiman, M. K. (2021). Mapping of Freshwater Snails' Habitat-A Source of Transmitting Bilharzia in Mwea Sub-County, Kenya. Journal of Geoscience and Environment Protection, 9, 130-150.

https://doi.org/10.4236/gep.2021.910010

Received: June 15, 2021

Accepted: October 24, 2021

Published: October 27, 2021

Copyright $\odot 2021$ by author(s) and Scientific Research Publishing Inc. This work is licensed under the Creative Commons Attribution International License (CC BY 4.0).

http://creativecommons.org/licenses/by/4.0/

(c) (i) Open Access

\begin{abstract}
Bilharzia is vector-borne disease carried by a parasite that is hosted by fresh water snails. The distribution of the disease is concurrent with the existence of the freshwater snails and is dependent on certain suitable environmental conditions. It is difficult to identify the specific habitats of the snails as they are often inaccessible on the ground, the snails also migrate by means of flowing water, making it difficult to keep a track of the freshwater snails' habitat. This paper aimed at using GIS, Remote Sensing and Species Distribution Modelling techniques to model the suitable habitats for the freshwater snails and to prove that the snails migrate when there are sudden changes in water levels whilst showing the population at risk of bilharzia. The SDM used is the Maximum Entropy (MAXENT) for its ability to make right predictions even with small presence sites. The AUC value of the model was 0.951. The research results showed that the environmental variables; brightness Index, elevation, temperatures were negatively correlated with the snails' presence while the wetness index, MSAVI, greenness index and soil $\mathrm{pH}$ were positively correlated. The snails are observed to favor clay soils of the montmorillonite type and the crop-lands land cover. Areas consistently submerged by water especially after flooding are shown to be the most suitable areas where snails migrate by means of river or canal water. The research proves that Mwea is not the source habitat of the freshwater snails. The neighboring sub-counties within Kirinyaga County should be investigated using such models as a likely source-habitat of the freshwater snails. Destroying the source habitats will lead to complete eradication of the freshwater snails within Mwea.
\end{abstract}

\section{Keywords}

Area Under Operating Curve (AUC), Species Distribution Models, Maximum Entropy (MaxEnt), Land Surface Temperatures, Geographic Information 
Systems, Remote Sensing, Land Use Land Cover

\section{Introduction}

Bilharzia as a neglected tropical disease is second to malaria in its adverse effect on public health and socioeconomics impact in the tropics and sub-tropics of the developing countries (Manyangadze et al., 2016).

It has a risk of infecting 6 million people in Kenya 70\% being between 5 - 14 years. The infection occurs when a person comes into contact with water that has parasitic worms that develop inside the host freshwater snails. The worms enter through the skin or through drinking infected water. The problem with Bilharzia is two-fold. One, it can cause permanent damage to vital body organs such as liver and the uterus if left untreated. Two, it has no vaccine and although it can be treated; it has been reported to re-occur (Mitra \& Mawson, 2017).

This paper therefore proposes the identification and destruction of snail habitats as a way of totally eradicating Bilharzia.

Previous studies have explored this idea in different ways. Seto et al. (2002) identified that controlling the gates of the water canals such that snails could not get into the farms had a great contribution in reducing consequent snail habitats. Another study proposed that GIS techniques could be used to understand the distribution of snails on a broad scale. This study further suggested the use of temperatures and vegetation distribution to identify the relationship between the snails and the environment (Brooker, 2002). In Zimbabwe MaxEnt was found to be highly useful in mapping of snail's habitats in small regions. In this study the researchers used HIRHAM5 climate model to predict the future distribution of snails (Pedersen et al., 2014). Other studies have explored the dynamics of correlating the environment variables a snail is dependent on for survival than using statistical analysis to improve accuracy of the results and finally displaying the distribution of the snails (Zhang et al., 2005). The study however used a few variables which translated to the state of the soil and the vegetation. Finally, one study identified the change in water levels as a mode of transmission especially during floods (Shi et al., 2017). The paper utilized statistical modelling and GIS and Remote Sensing to predict habitats for snails after flooding.

Our study therefore used Remote Sensing, GIS techniques and Species Distribution Modelling to simulate the freshwater snails' habitats in such a way that the inaccessible locations that harbor the snails can be identified. The above techniques make it clear which areas actually have the snails versus those that seem to have the snails and yet they do not. These techniques in turn will cover large areas, inaccessible areas and will give governments specific targets that will eradicate the freshwater snails while reducing costs of eradication.

The objectives of this study were to: 1) Map potential habitat areas of the freshwater snails. 2) Prove that the freshwater snails spread based on flooding 
and changes in water levels. 3) Model population at risk of infection based on closeness to the potential habitat.

\section{Materials and Methods}

\subsection{Study Area}

The study area (Figure 1) covers Kirinyaga County and in particular the southern region of the county i.e. the Mwea East and Mwea West sub counties. At an altitude of about $1200 \mathrm{~m}$ above sea level, Mwea lies at the foot of Mt Kenya. Several perennial rivers flow within this region and due to the poor drainage of the soils the region has several swamps and this has led to the establishment of rice irrigation schemes and paddies including the famous Mwea Teberre Irrigation Scheme. Several water canals distribute water to the various paddies and in turn also transport snails.

The climatic conditions are such that they favor breeding of various pests e.g. mosquitoes and freshwater snails. The mean annual rainfall in this area is in the range of $1200-1600 \mathrm{~mm}$ per year and varies by the time of year. The long rains

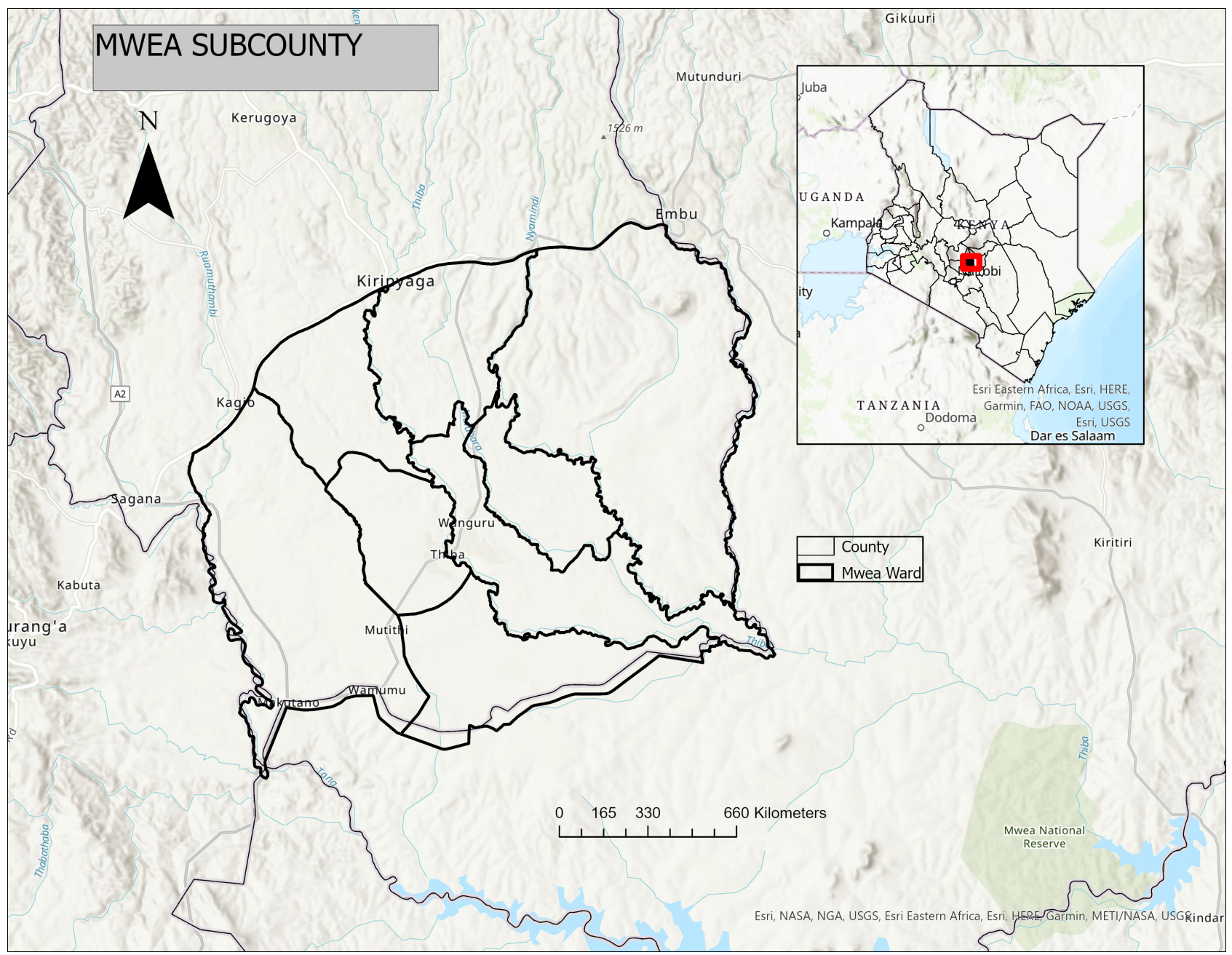

Figure 1. Study area. 
usually come from March to June and the short rains from October to December. The mean temperatures in the region vary from $23^{\circ}$ Celsius to $25^{\circ}$ Celsius. The soils in the region are black cotton soils with high water retention capacity.

\subsection{Data}

Landsat 8 OLI satellite imagery for 2019 was acquired from USGS website. Radiometric and atmospheric corrections were first carried out on the imageries before using the imagery. Two Sentinel-1A imageries, (one for during the collection of data period) and the (second one for the rainy or after floods) season in Mwea were acquired from the Copernicus website. Pre-process the Sentinel images by calibration, and speckle filtering using SNAP software. Snail sites were picked by use of GPS from the field in Mwea. Elevation data was acquired from the Shuttle Radar Topographical Mission (SRTM) from USGS website. Land use data was acquired from MODIS satellite. Population data was extracted from WorldPop website. Soil data was acquired from Diva-GIS website.

\subsection{Methods}

In carrying out this research, the environmental variables representative over the region were extracted from the Landsat 8 imagery. The indices extracted were; MSAVI, Land Surface Temperature, the tasseled cap indices-that is wetness index, greenness index and brightness index. The extraction is done by combination of different bands using a raster calculator. The product is a raster map of the resulting indices.

In order to use the MaxEnt model as an SDM, it is important to increase accuracy by tuning the model using the enmEvaluate (EnmEval). EnmEval tunes the model to maximize its predictive ability while avoiding overfitting by utilizing goodness-of-fit parameters. The EnmEval is developed using the R-software. In the process, data is partitioned then cross-validated using the jackknife technique. The pseudo-absences used as background points are assigned 10,000 in number. In R-software, one uses the snail site occurrences and overlays them over the covariates to extract similarities and differences. The maxent model then replicates these similarities and differences over the rest of the map area.

Using the output from the above process (which is a bias file) one adjusts the settings on the MaxEnt Software. Query the software to use maximum entropy model to predict the suitable habitats for the snails.

In order to simulate the spread of freshwater snails based on changes in water levels one uses Sentinel-1A imageries. Process the sentinel images using SNAP software and set thresholds on the images using it. After thresholding the images extract the submerged and the non-submerged areas.

To develop a Bilharzia Risk Map, we use population data and the simulated spread of snails' map. Carry out spatial smoothing on the population data for Mwea. Spatial smoothing is carried out using raster calculator and kernel density estimator tools. The product is continuous surfaces of intensity. Derive risk 
function by using the formula (Simarro et al., 2012);

Formula (1)

$$
\hat{R}_{\tau}(s)=\hat{D}_{\tau}(s) / \hat{P}_{\tau}(s)
$$

where; $D_{t}(s)=$ average estimates of snail occurrence

$P_{t}(s)=$ average annual estimates of population density

$R_{t}(s)=$ Risk Function

Apply a threshold to $R_{t}(s)$ to categorize the risk factor as either high, medium or low on the resulting map which is a risk map. The thresholds are determined as follows (Simarro et al., 2012):

$$
\begin{aligned}
& R(s) \geq 0.06 \text { High Risk } \\
& R(s) \geq 0.03<0.06 \text { Medium Risk } \\
& R(s) \geq 0.01<0.03 \text { Low Risk }
\end{aligned}
$$

\section{Results and Discussion}

\subsection{Covariates Processing and Results}

Using the raster calculator and the formulas below, indices are extracted from Landsat 8 OLI imagery. The results were various raster maps

MSAVI Landsat 8 , MSAVI $=(2 *$ Band $5+1-\operatorname{sqrt}((2 *$ Band $5+1) 2-8$ * (Band 5 - Band 4)))/2.

\section{Equation (2) of MSAVI}

The MSAVI index is used when one intends to minimize the soil background influence and to increase the dynamic range of vegetation signal. The index (Figure 2) indicates that the study area has a small range of vegetation covering the area with the majority of the area being covered majorly and roughly by bare soil. The vegetated areas are actually the rice fields. The region has sparse vegetation except where the croplands are located.

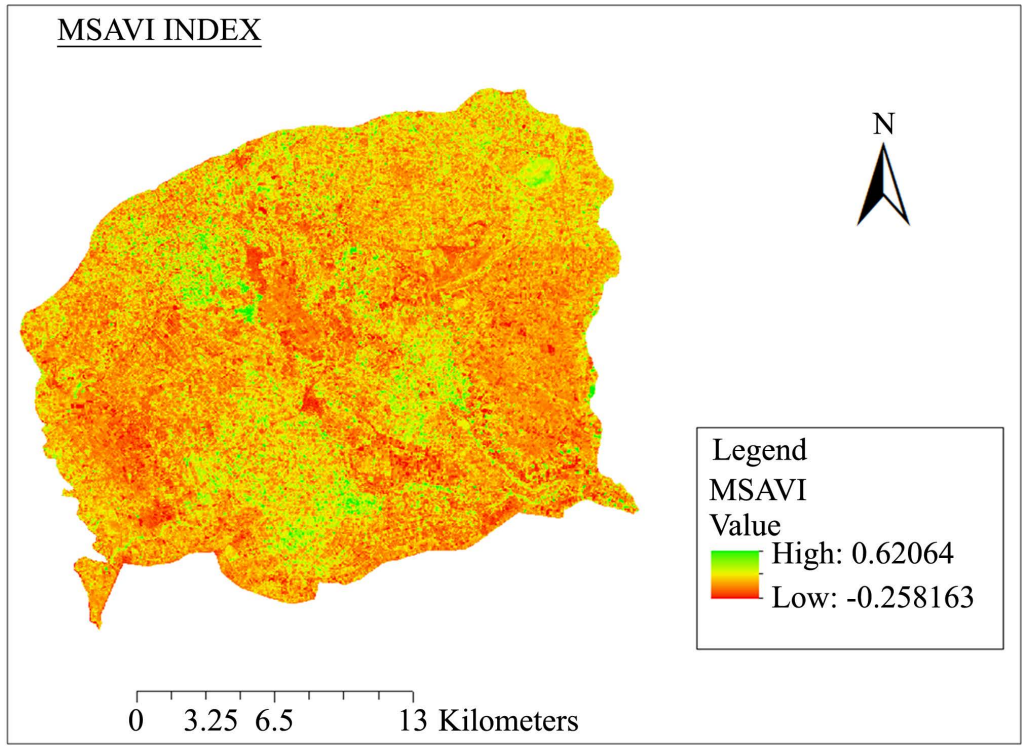

Figure 2. MSAVI index. 
Wetness Index $=0.1509($ band 1) $+0.1973($ band 2) $+0.3279($ band 3$)+$ 0.3406 (band 4) -0.7112 (band 5) -0.4572 (band 7)

\section{Equation (3) of Wetness Index}

The wetness index (Figure 3) indicates the soil moisture status. The green (highest) values represent the areas with croplands in particular rice paddies, the areas also comprise areas where the rivers have started flooding. The lower wetness index areas comprise of mainly the savannah areas with grasslands areas having the lowest wetness index (purple color).

Brightness index $=0.3037($ band 1) $+0.2793($ band 2) +0.4743 (band 3) + 0.5585 (band 4) +0.5082 (band 5) +0.1863 (band 7)

\section{Equation (4) of Brightness Index}

The brightness index (Figure 4) measures the soil reflectance or the total reflectance. The region generally has low reflectance values; probably due to having large areas covered by vegetation or water. The rice fields have the lowest reflectance probably due to the rice crop being densely grown and hence the soil can barely be seen or remotely sensed. The grassland areas (the eastern side) have the highest soil reflectance meaning the presence of sparse grass land cover.

Greenness index $=-0.2848$ (band 1) -0.2435 (band 2) -0.5436 (band 3) + 0.7243 (band 4) +0.0840 (band 5) -0.1800 (band 7)

\section{Equation (5) of Greenness Index}

The greenness index (Figure 5) measures the vegetation spectral information, i.e. the level of chlorophyll. The results indicate that the region has very sparse green vegetation which is mainly located within the croplands land cover.

LST is calculated in the following ways:

1) TOA (Top of Atmospheric) spectral radiance

$$
\mathrm{TOA}(\mathrm{L})=\mathrm{ML} * \mathrm{Qcal}+\mathrm{AL}
$$

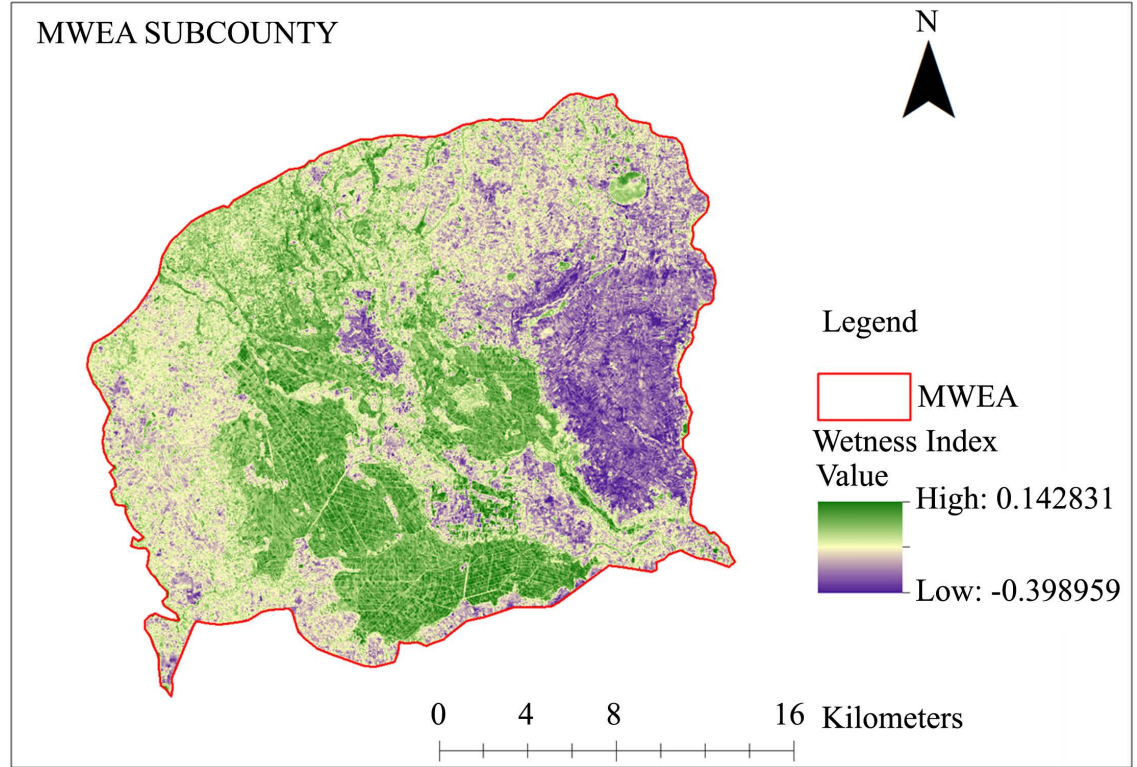

Figure 3. Wetness index. 


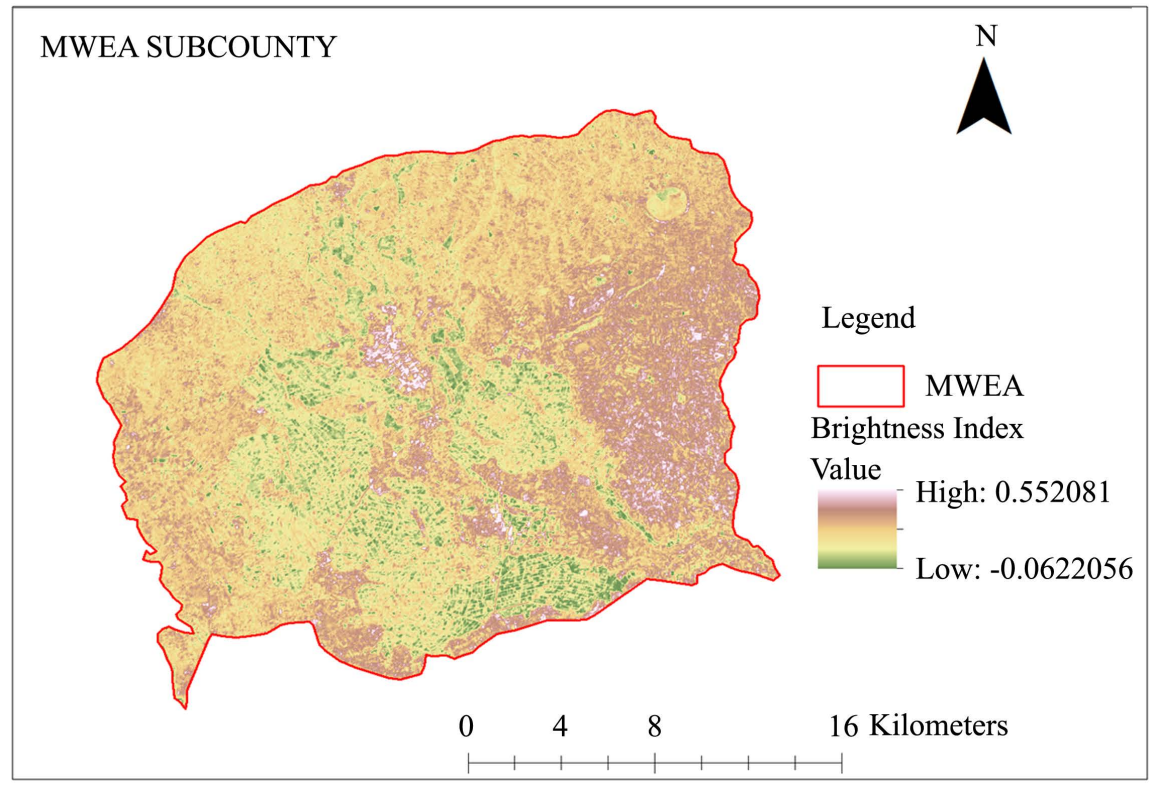

Figure 4. Brightness index.

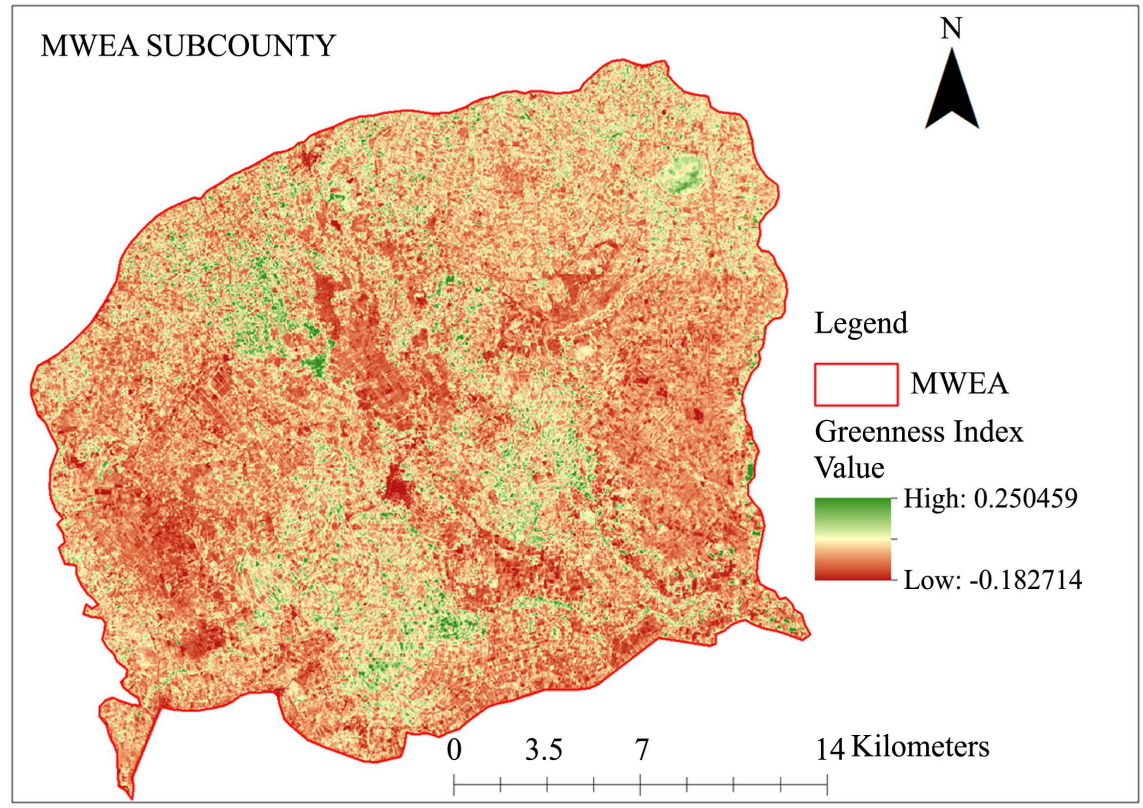

Figure 5. Greenness index.

where:

$\mathrm{ML}=$ Band-specific multiplicative rescaling factor from the metadata (RADIANCE_MULTI_BAND_ $\mathbf{x}$, where $\mathrm{x}$ is the band number).

Qcal $=$ corresponds to band 10 .

$\mathrm{AL}=$ Band-specific additive rescaling factor from the metadata (RADIANCE_ADD_BAND_ $\mathbf{x}$, where $\mathrm{x}$ is the band number).

2) TOA to Brightness Temperature Conversion

$$
\mathrm{BT}=(\mathrm{K} 2 /(\ln (\mathrm{K} 1 / \mathrm{L})+1))-273.15
$$


where:

$\mathrm{K} 1$ = Band-specific thermal conversion constant from the metadata (K1_CONSTANT_BAND_ $\mathbf{x}$, where $\mathrm{x}$ is the thermal band number).

$\mathrm{K} 2$ = Band-specific thermal conversion constant from the metadata (K2_CONSTANT_BAND_x , where $\mathrm{x}$ is the thermal band number).

\section{Equation (6) of LST}

LST is the radiative skin temperature of the land surface as measured in the direction of the remote sensor. It's a mixture of vegetation and bare soil temperatures and it determines the surface air temperature. The LST is greatly affected by the land cover. In Mwea its observed that the croplands (rice paddy fields) have the lowest surface temperatures while the savannah, grasslands and built-up environment respectively have the highest surface temperatures (Figure 6).

Land Use Land Cover can be obtained directly from a classified MODIS imagery from USGS website. One, however, has to convert the vector product back to raster product and re-assign the classifications.

The region is mainly covered by grasslands and savannah. The region has a very small region which is urban/built-up, this is because the region has been established mainly for rice growing within the Mwea irrigation scheme (Figure 7). The cropland region can only be suitable at the particular central and south region because of the river flow dynamics and the elevation; this is so as to allow irrigation.

Montmorillonite is a very soft phyllosilicate group of minerals that form when they precipitate from water solution as microscopic crystals, known as clay. Kaolinite clay is also called white clay and commonly used as an industrial mineral due to being rich in kaolinite. The rice fields favor the regions of montmorillonite clay due to acidic $\mathrm{pH}$ while the kaolinite clay is quite neutral in soil $\mathrm{pH}$ (Figure 8 and Figure 9).

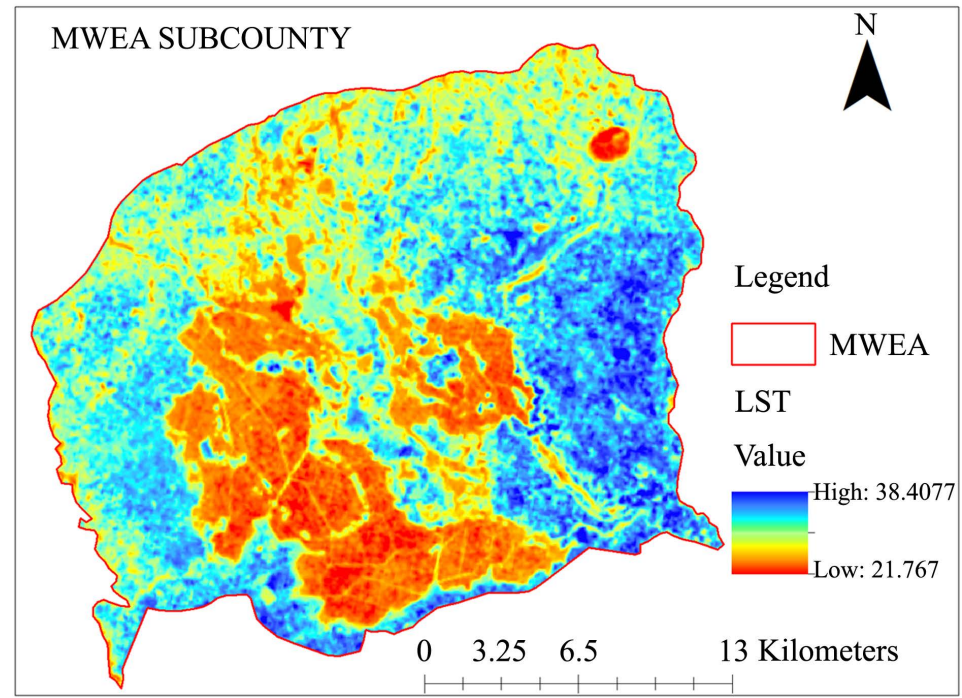

Figure 6. Land surface temperature. 


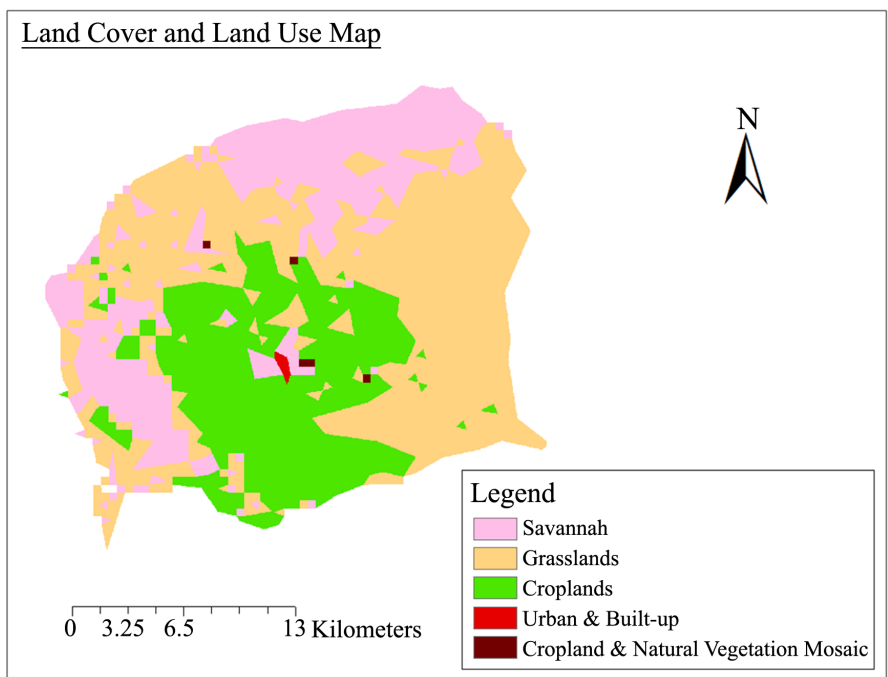

Figure 7. Land use land cover.

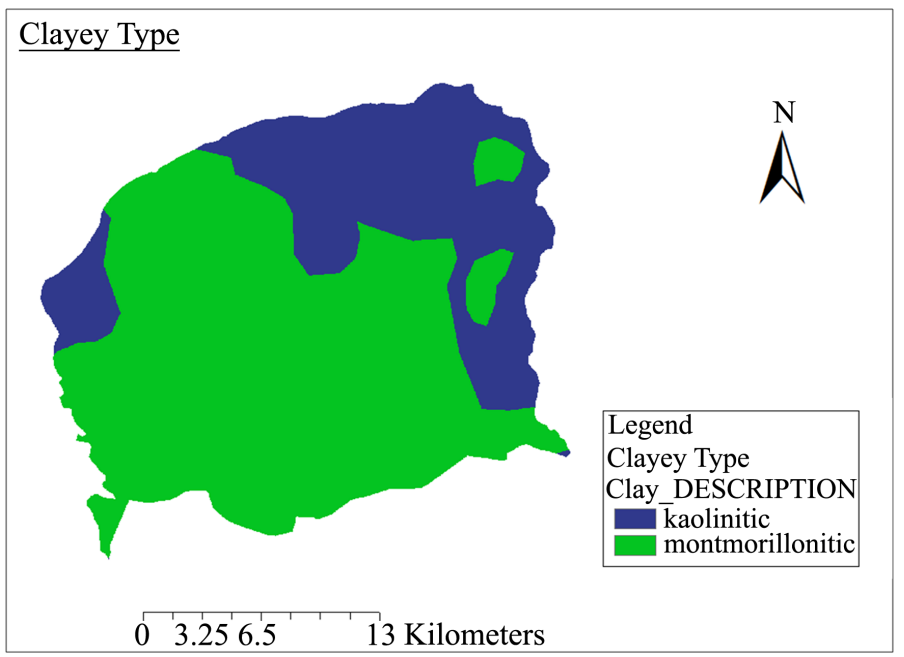

Figure 8. Clayey type.

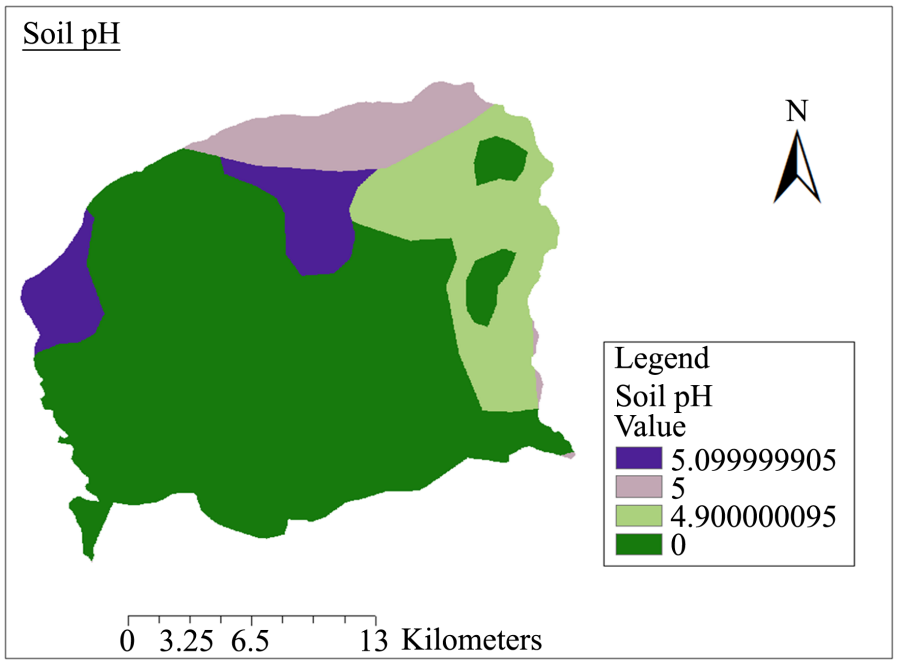

Figure 9. Soil $\mathrm{pH}$. 
The region generally has a basic soil potential of hydrogen. This is influenced by the presence of the clayey soil which majorly acidic to neutral i.e. $(0-7 \mathrm{pH})$. The literature review also indicates that the higher the $\mathrm{Ph}$ the more the ability of the environment to support the survival of other water-borne causing organisms, but this is vice versa for the survival of the snails. The snails favor acidic soils to basic soils.

The region is fairly high at an average altitude of about 1350 meters above sea level (Figure 10). The whole land seems to be significantly level which favors the growth of rice. The land slope from the North to the South East region which is also proven by the flow of the major rivers.

\subsection{Variable Response Curves and Graphs}

The MaxEnt software carries out a regression analysis within itself to determine the relationship between the variables and the probability of the environment to be suitable for the survival of the snails.

The soil type, clayey type and the LULC are categorical variables which means the software ranked the most suitable category by assigning the category a number. The other variables are interpreted as continuous variable surfaces.

1) Brightness Index and Greenness Index Response

Suitability of the environment decreases with increase in brightness index of the soil. This can be interpreted in different ways. One is that the snails do not favor open soil areas. The snails are therefore favored by soils which have cover; preferably vegetation or water. Two, this paper proves that the snails are mainly found in the rice irrigation areas since the brightness index map indicates that those regions are the ones with the lowest brightness (Figure 11).

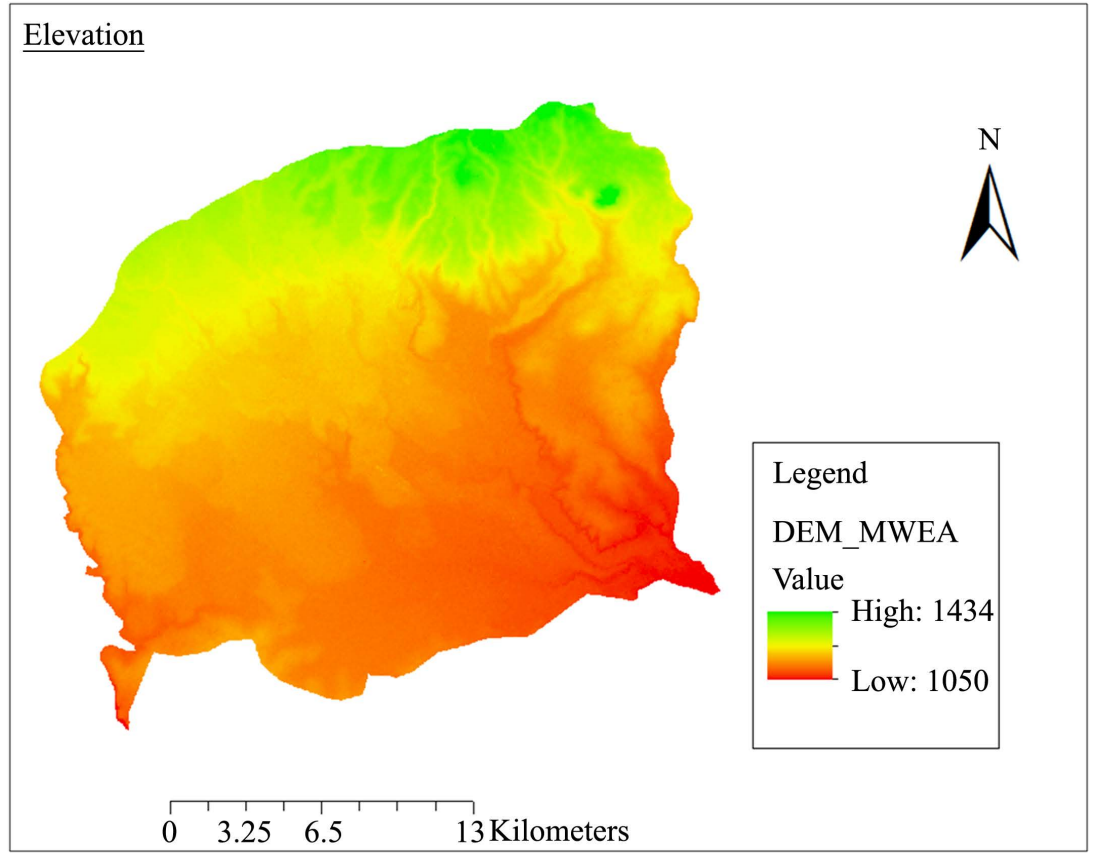

Figure 10. Elevation. 


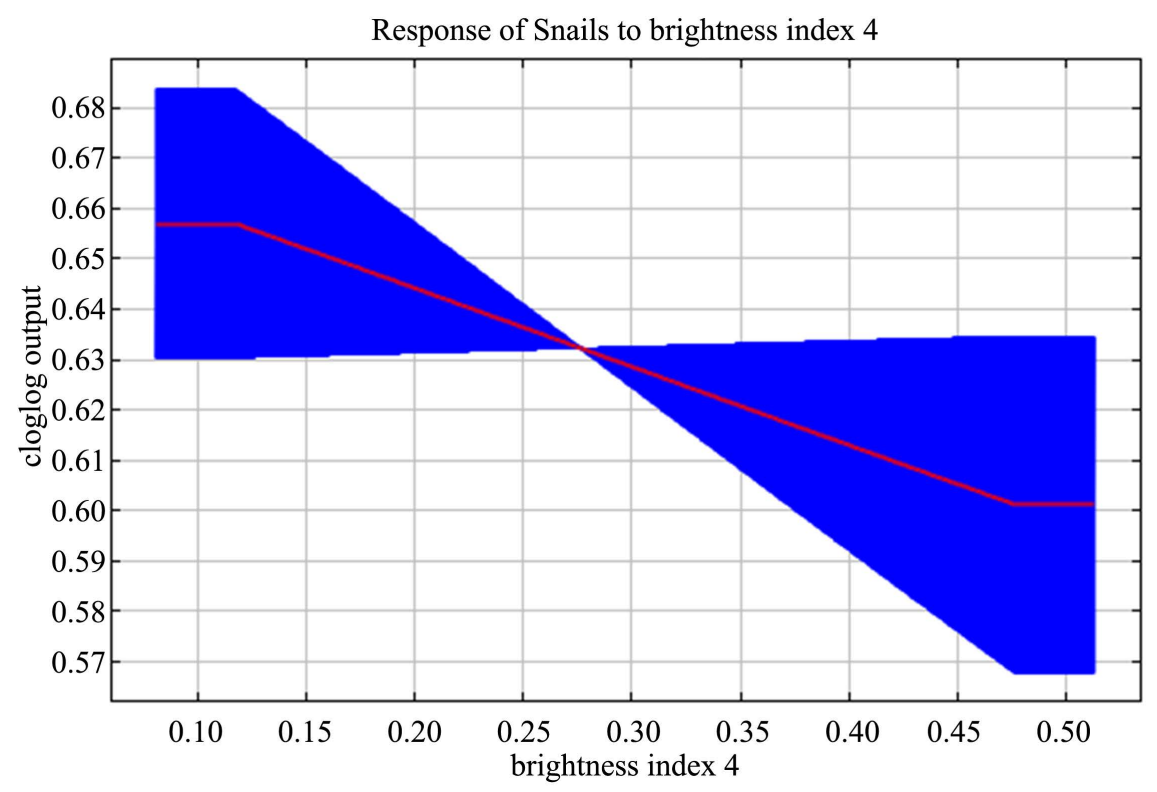

Figure 11. Response curve brightness index.

The suitability of the environment for the survival of snails increases with increase in the greenness index. Since greenness index measures the level of chlorophyll reflectance; then the results of the graph can be interpreted as follows. A habitat which is suitable for the freshwater snails should have green vegetation cover. Where the ground has little or no green vegetation; then the snails are rare. This is consistent with our studies since snails are found to feed on green vegetation which is inclusive of the rice shoots and leaves (Sanico et al., 2002). The young rice seedlings serve as food for the snails (Figure 12).

2) Elevation and Wetness Index Response Curves

The region slopes towards the south west direction as shown in elevation map above. Elevation increase leads to a decrease in the suitability of the environment for snail survival (Figure 13). This is because lower altitudes favor slow flow of water which encourages breeding while higher altitudes encourage migration by water flow. Most snail habitats are found to be where the speed of the flow of water is reduced. The places where water has been diverted for rice irrigation have been found to have most snails. The farmers can be advised to have water flowing at faster speed to prevent snails from lodging on the vegetation.

The increase of soil moisture (wetness Index indication) leads to higher suitability of the environment to support snails up to a certain level (Figure 14). The decreasing levels of soil moisture lead to the aestivation of the snails. Long periods of reduced soil moisture can lead to the death of these snails. Farmers can be advised to drain their rice paddies after maturation stages and harvesting of rice so as to kill the freshwater snails.

3) Clayey Soil and Soil Type Bar Graph Response

Soil type that is highly favorable is the very clayey soil of the montmorillonite type. This soil has high adsorption capacity. That is, it is able to hold water within it for a long period of time (Li et al., 2014). This soil favors the habitation 


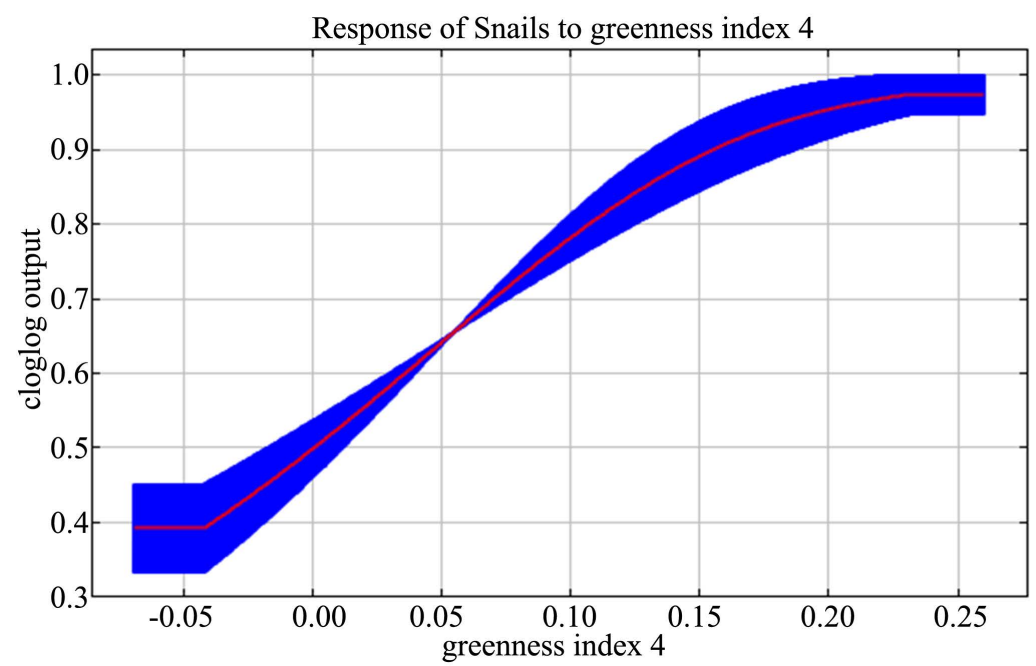

Figure 12. Response curve greenness index.

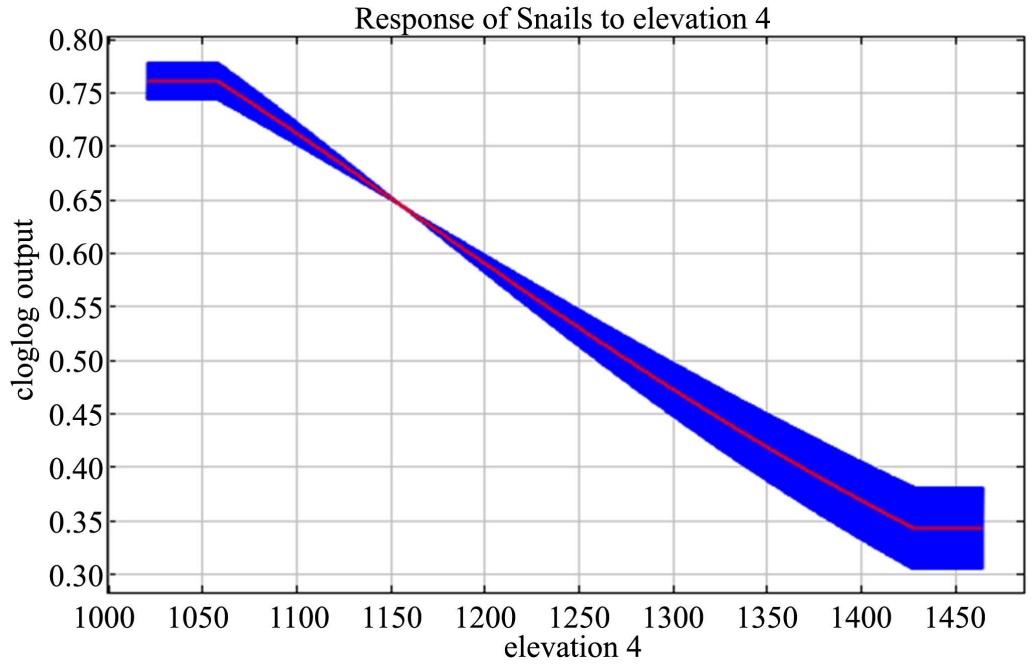

Figure 13. Response curve elevation.

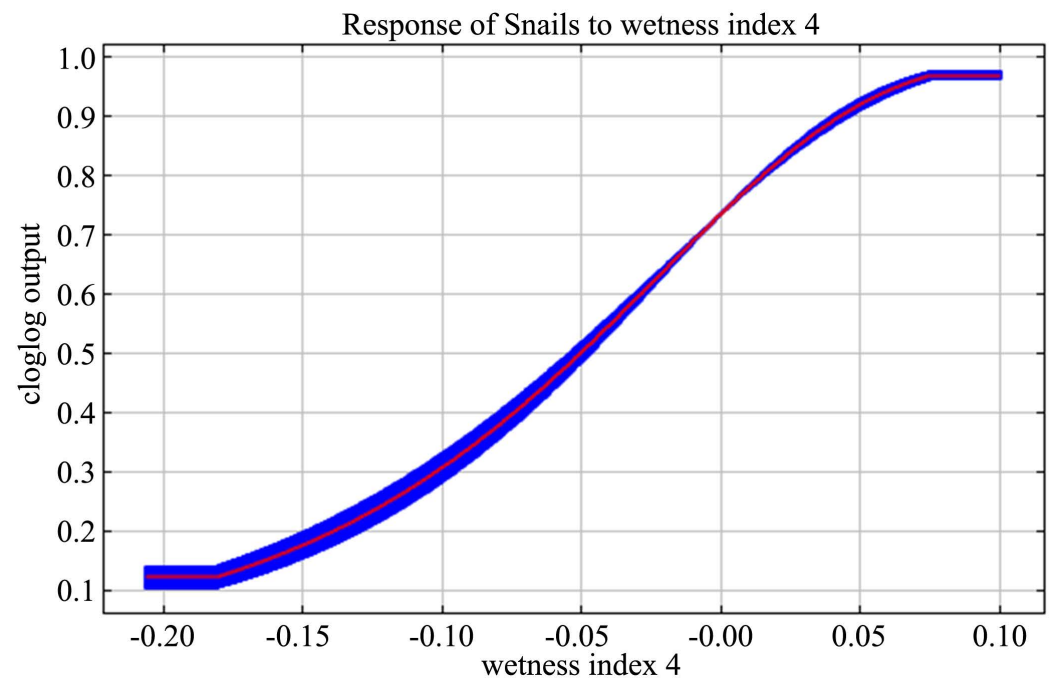

Figure 14. Response curve wetness index. 
of freshwater snails because these snails can rely on this soil to retain water necessary for their survival for a long period of time (Figure 15 and Figure 16).

4) Land Cover Land Use (LCLU) Bar Graph and Soil Ph Response Curve

a) The snails favor the croplands land cover (12). The LCLU ranked as 9, 10, 13 and 14 represent the savannahs, grasslands and cropland vegetation mosaic respectively (Figure 17). The cropland vegetation presents vegetation which has chlorophyll in them. As mentioned earlier, this vegetation feeds the snails. The snails are not favored by the other land covers such as the savannahs due to their lack of greenness and even low soil moisture content.

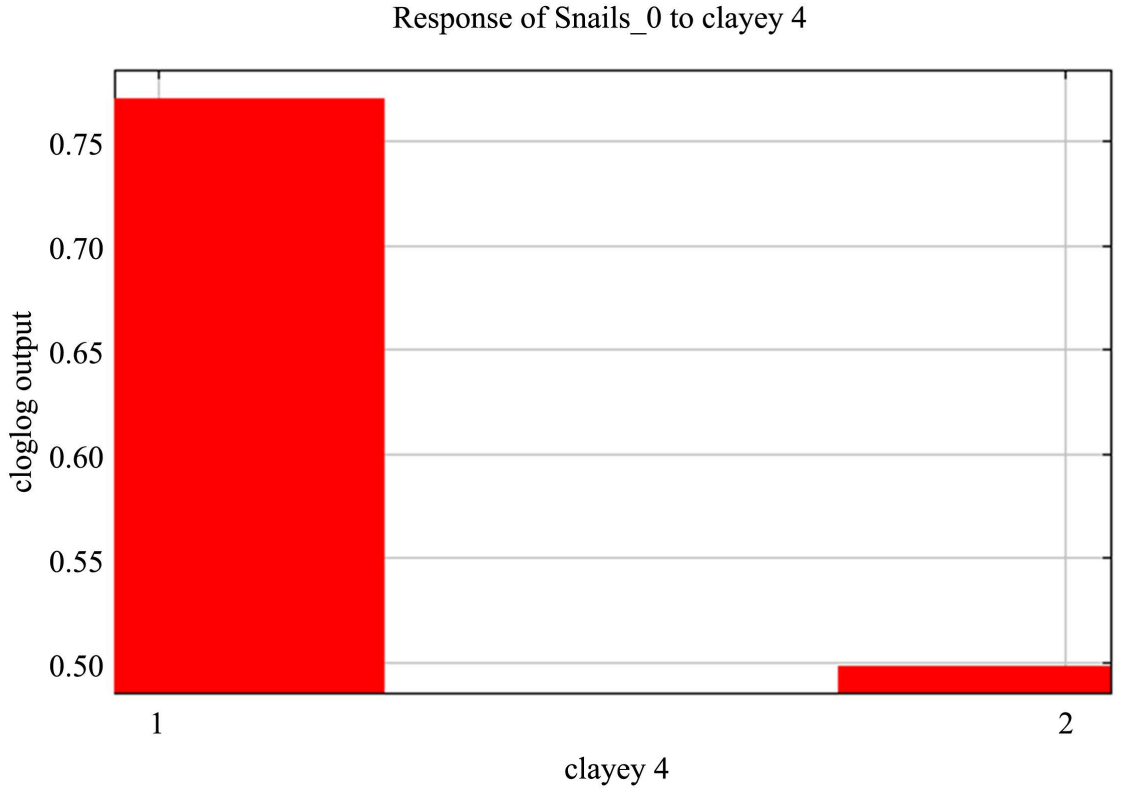

Figure 15. Response graph clayey type.

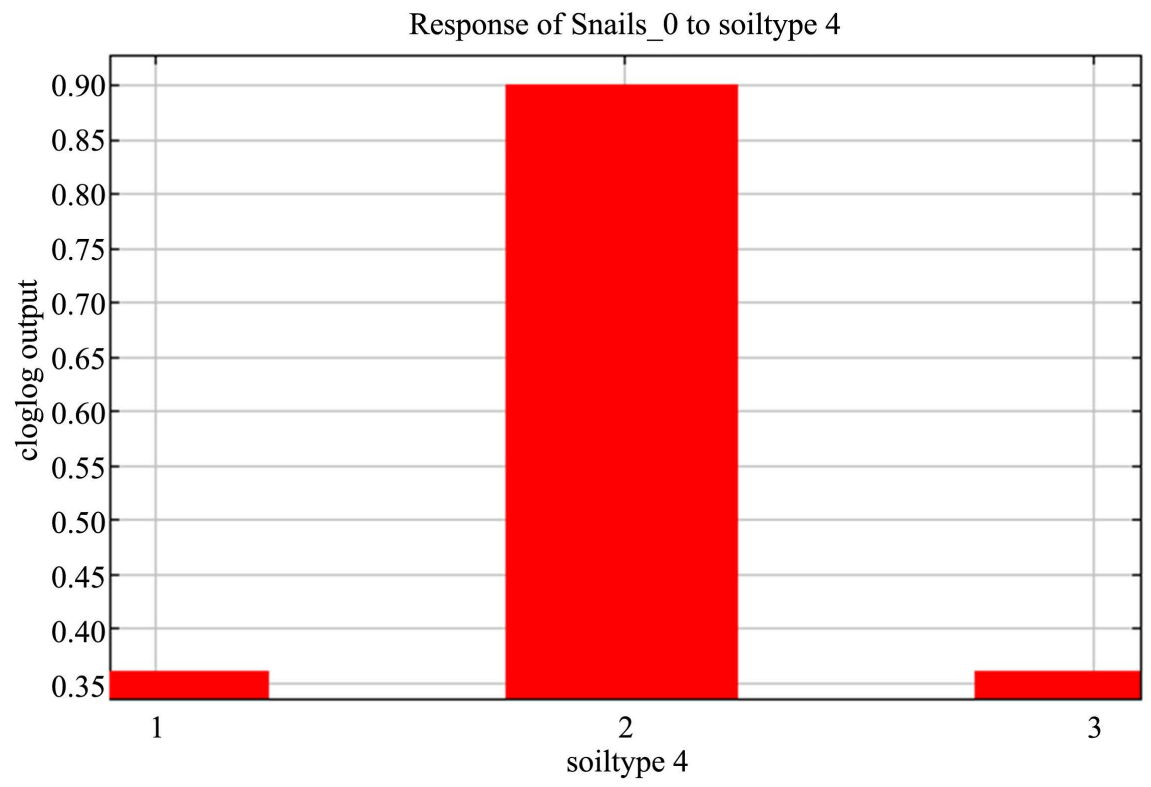

Figure 16. Response graph soil type. 
Response of Snails_0 to lclu 4

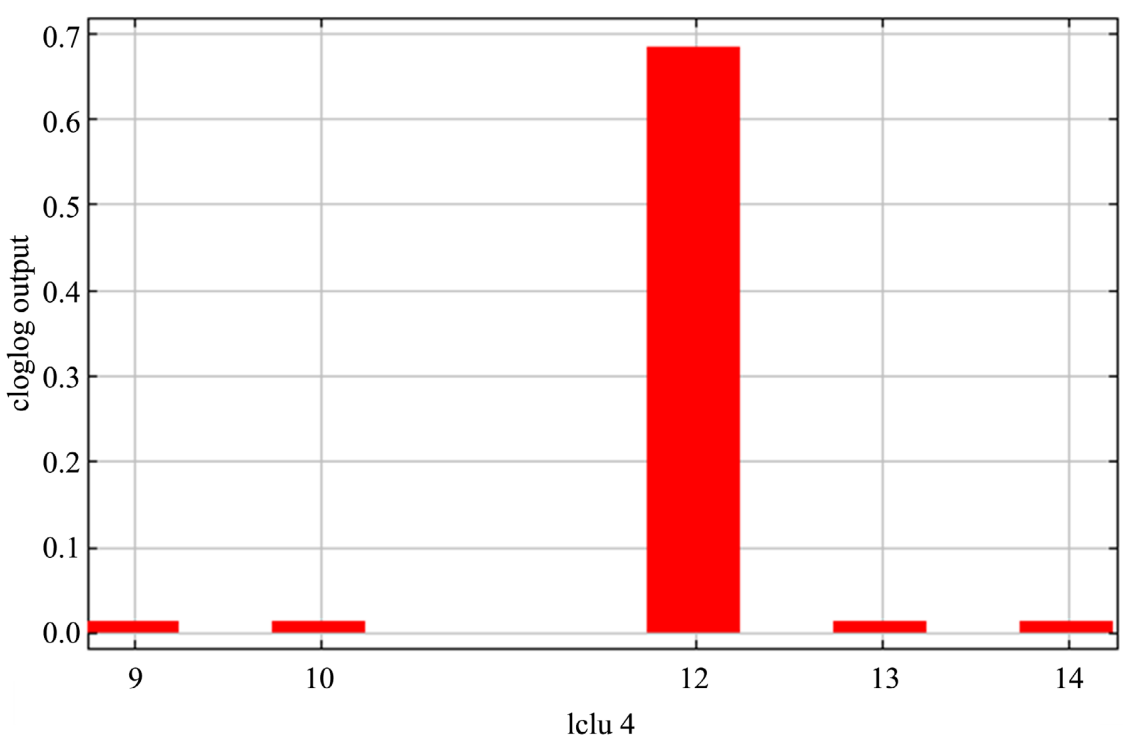

Figure 17. Response graph LCLU.

b) The increase of $\mathrm{pH}$ from 2.0 up to 4.5 favors the survival of the snails. The freshwater snails favor an acidic environment to a basic-pH environment (Figure 18). This could be because such acidity is already present in the montmorillonite clay soils. The snails may have adapted over time to survive in such environments.

5) MSAVI index and Land Surface Temperature (LST) Response Curve

a) The higher the value of MSAVI the more suitable the environment for freshwater snails (Figure 19). The graph indicates that the more the land has ground covered with green vegetation the more habitable it is to the freshwater snails. Bare soil is unfavorable to the snails.

b) Increase of land surface temperatures leads to a decrease in suitability of habitats for freshwater snails (Figure 20). This is because the higher the temperatures, the more the chances of aestivation leading to death of the freshwater snails. Lower temperatures promote higher soil moisture which favors the survival of the freshwater snails.

\subsection{Variable Importance-Jackknife Test and AUC}

The Jackknife test shows the variable performance within the model. It evaluates on average how the variable performed when it's on its own and then when its relating with the rest of the variables. The Jackknife test is also used to rank the importance of the variables in order of their contribution to the modelling of the habitats. The LCLU, LST and wetness index respectively, were found to be the most important variables for habitat mapping of the snails. The brightness index and elevation were found to be the least important. This means one can exclude them in the modelling and yet one will still have results which are adequately satisfying (Figure 21). 


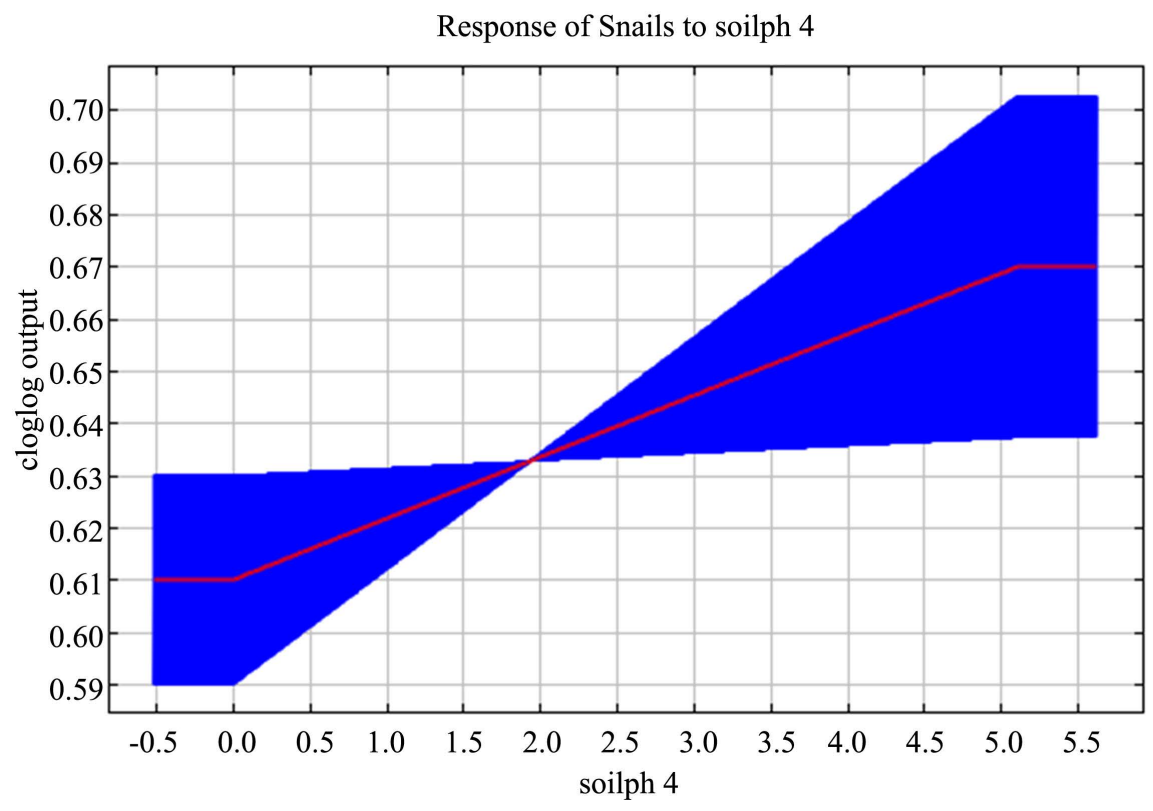

Figure 18. Response curve soil $\mathrm{pH}$.

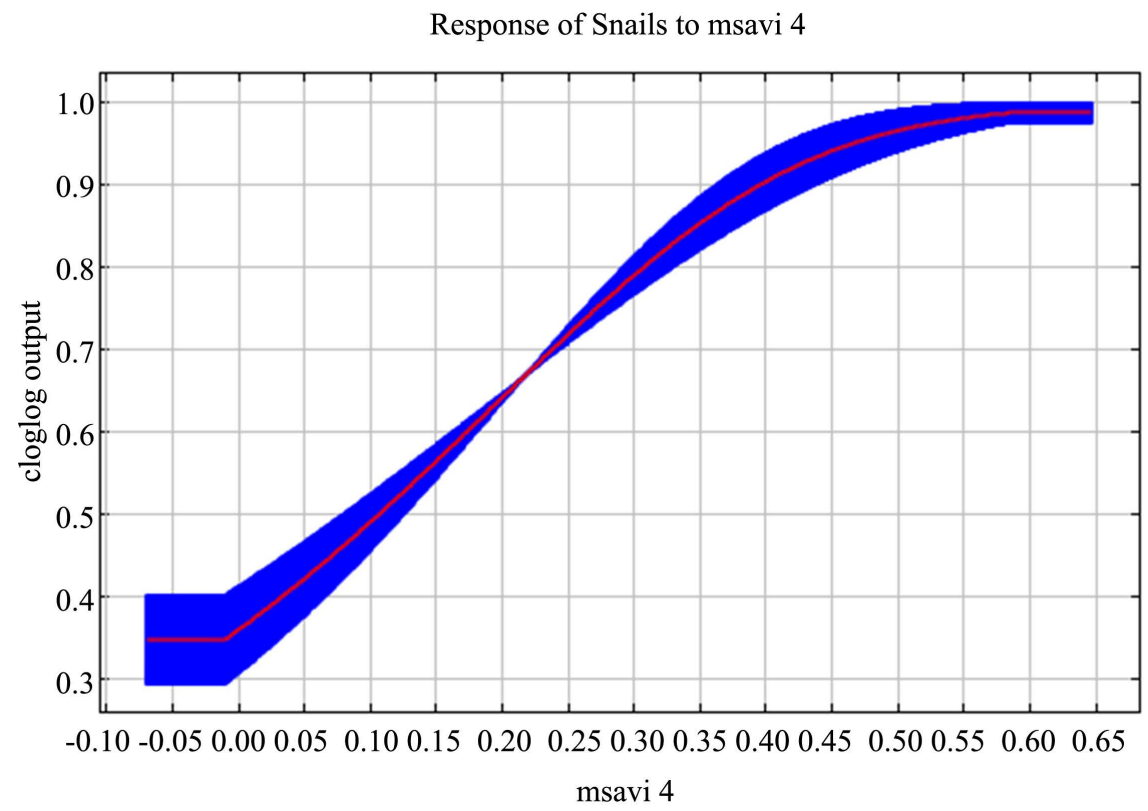

Figure 19. Response curve MSAVI.

The AUC on the other hand shows the model performance which can be compared to other models. When a MaxEnt model yields a value of below 0.5 then the model is said to have performed poorly. This could have been because the variable or site selection was poorly done. An AUC of $\geq 0.5-0.8$ indicates that the model performed averagely and that it performed just like any other model would have (Figure 22). A value of above 0.8 indicates that the model performed excellently. Our model had an AUC of 0.951 which means that our selection of variables and sites was excellent (Elith et al., 2011). 


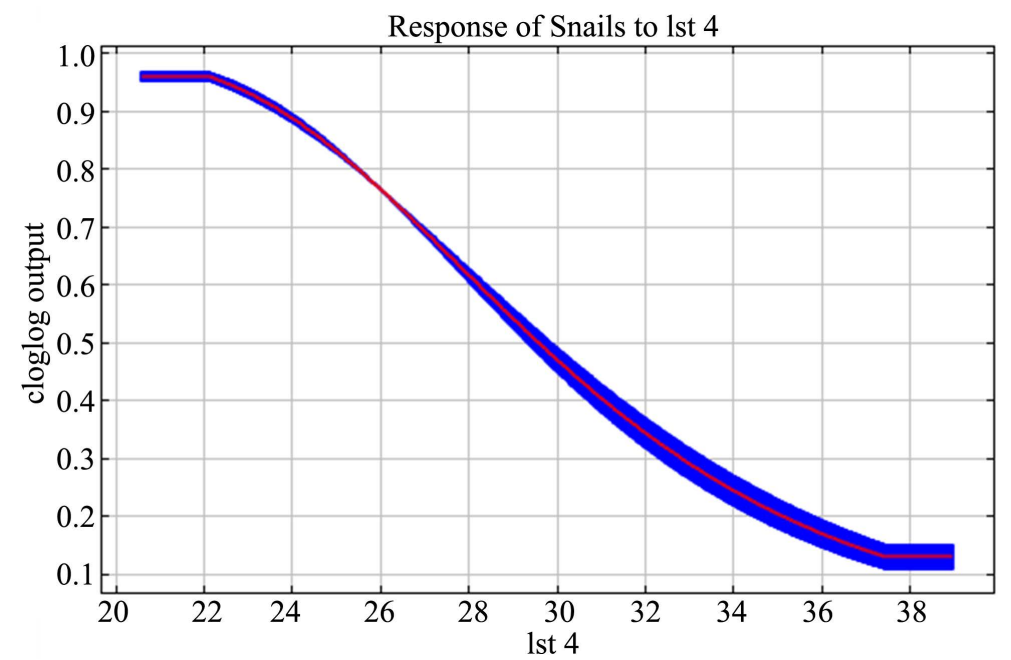

Figure 20. Response curve LST.

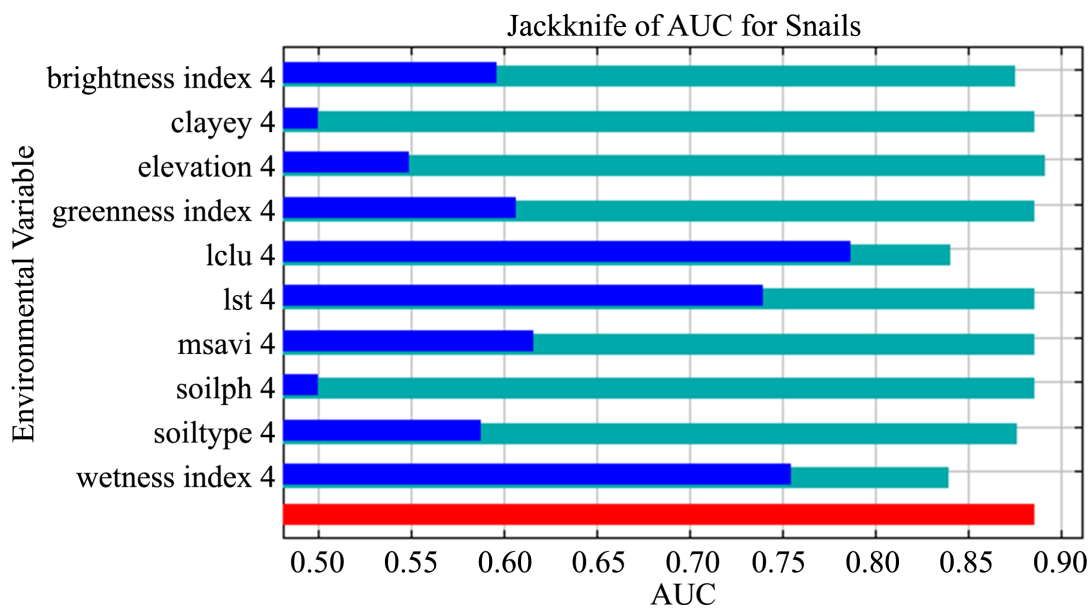

Without variable With only variable With all variables =

Figure 21. Jackknife test.

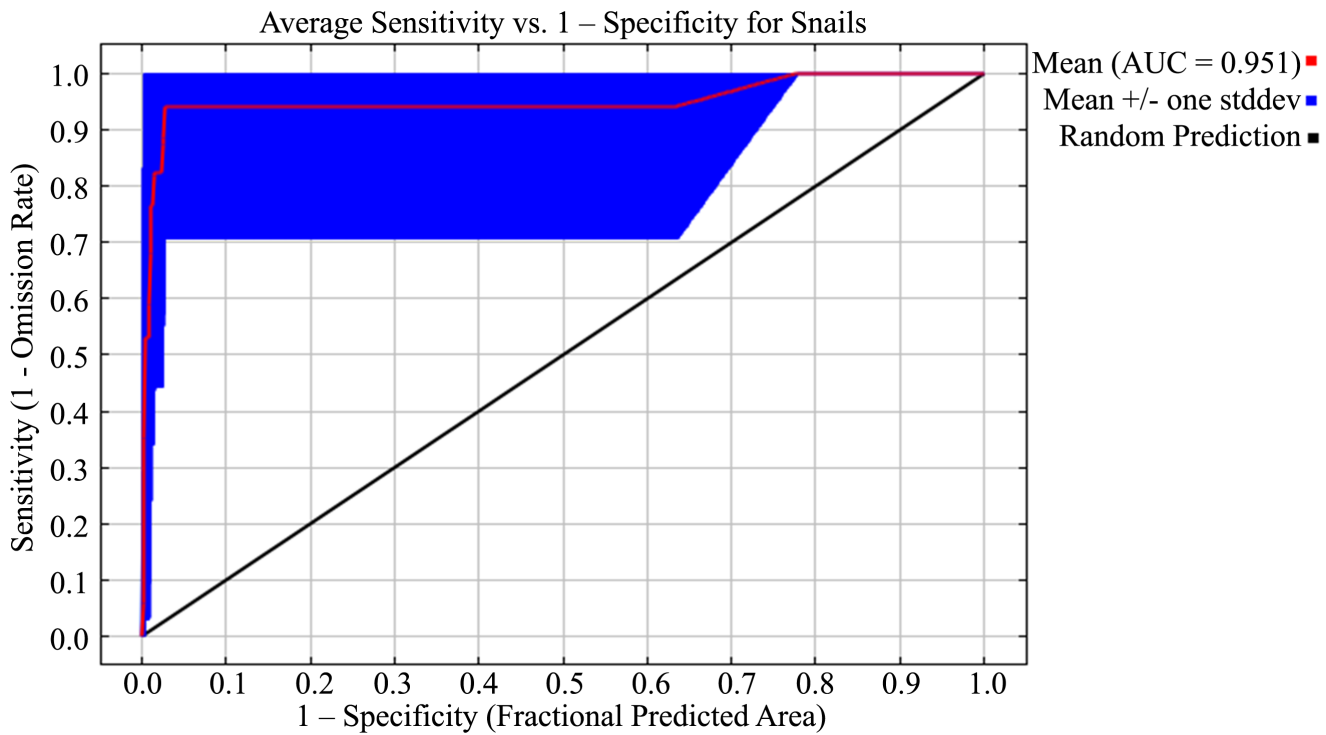

Figure 22. AUC test. 


\subsection{Maxent Results}

The combination of the different variables in a MaxEnt model yields the above map. The map ranks suitability of habitation from 0 - 1 .

Map (a) show the prediction of the model MaxEnt of the areas' probability to support the habitation of the freshwater snails.

Regions of the value (1) are of the highest probability to support the life of the freshwater snails while the lower the value of probability then the lower the probability of the specific region to support the habitation of the snails. The regions with higher probability of being suitable habitats for the snails are the rice paddy fields, irrigation scheme areas and the cropland land cover regions (Figure 23).

\subsection{Extraction of Submerged Areas}

The submerged areas are around the rice paddy fields and often close to the rivers. The results show that the higher the level of flooding in an area in Mwea then the higher the probability of that area to support the survival of snails. This is especially the case in the Gathigiriri and Thiba regions (Figure 24).

This same area is also found to be the habitats for the freshwater snails as shown in the comparison below (Figure 25).

\section{Comparing the flooded areas at the time versus the predicted habitats}

The flooded areas coincide with the resulting snail habitats. Since one understands that the flooded areas are also the habitat areas for the freshwater snails; then one can create a hypothesis. The hypothesis is that since flooding happens occasionally, then the floods carried the snails to the Mwea region. The elevation of Mwea region makes it suitable for the snails to settle and multiply there (Shi et al., 2017). One can assume that the source habitats for the snails are probably areas which have higher elevations and are the sources of the rivers flowing into Mwea.

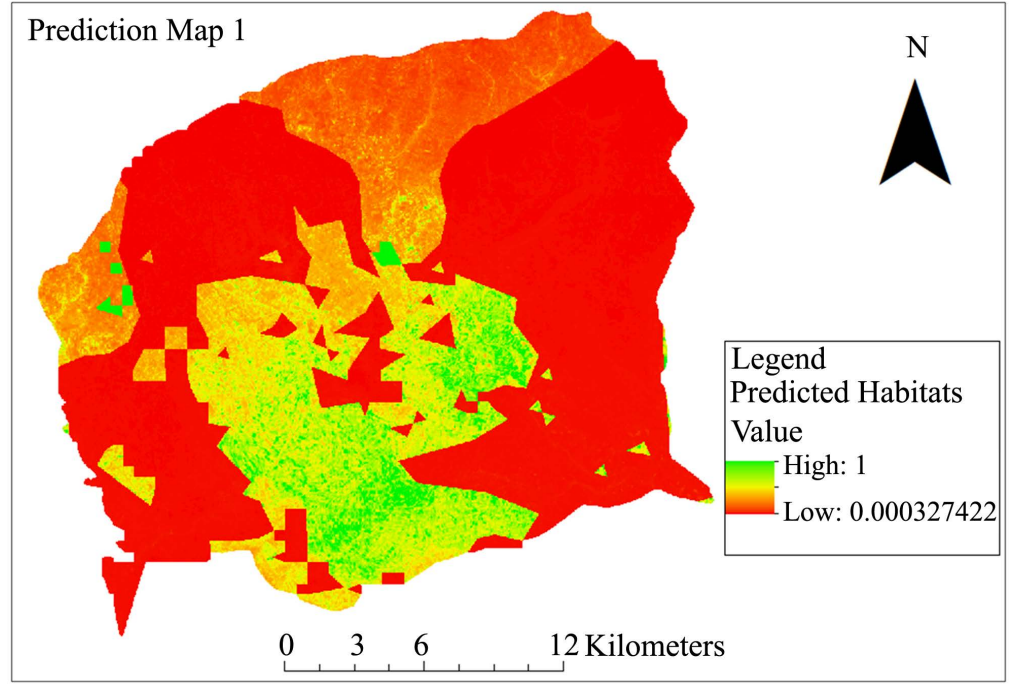

Figure 23. Snails habitats. 


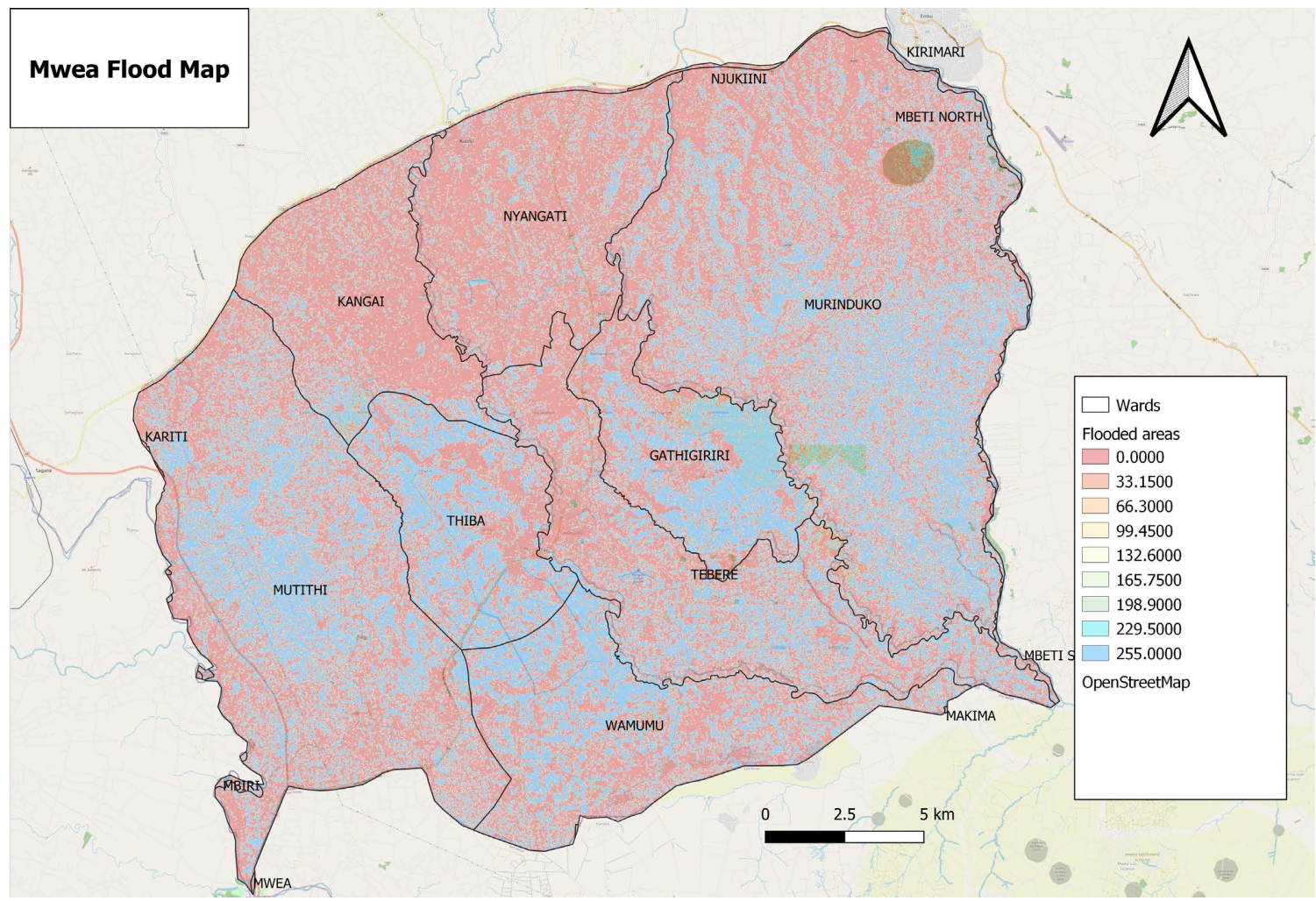

Figure 24. Flooded areas map.
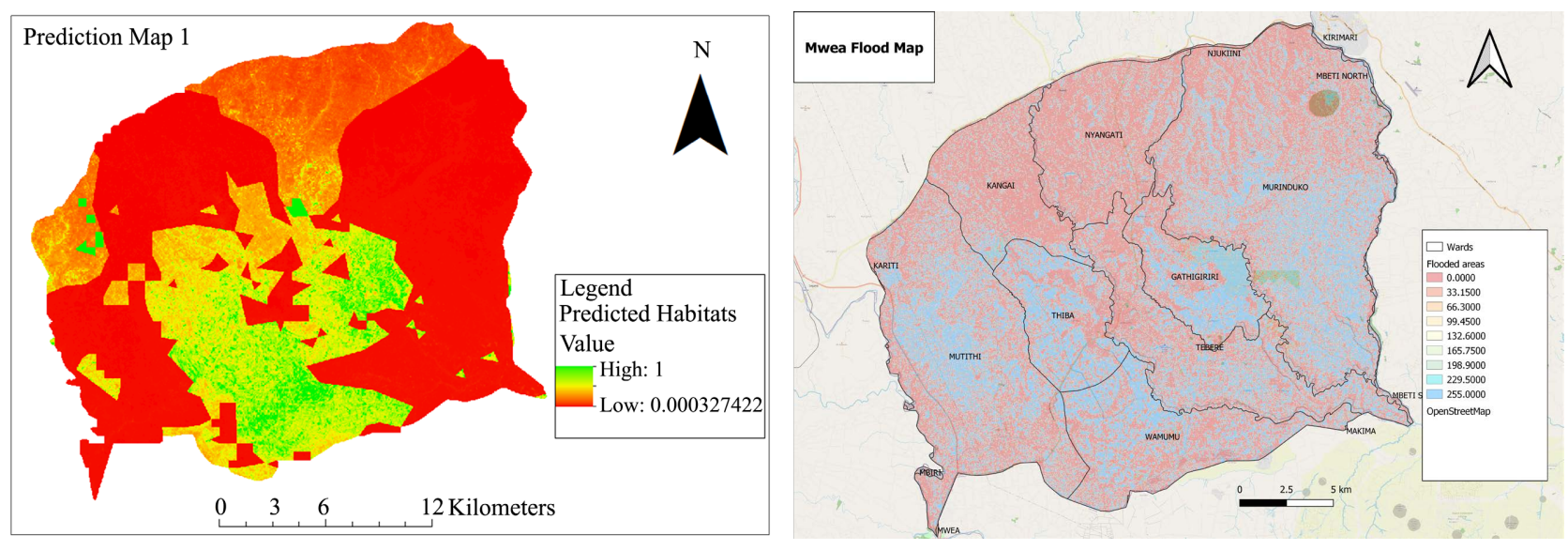

Figure 25. Comparison of habitats and flooded areas.

\subsection{Bilharzia Risk Map}

1) Mwea Population

The white areas (Figure 26) highlight places that have no people living there, these areas are actually the paddy fields or inaccessible areas. These areas are found to be the probable habitats of the freshwater snails.

2) Bilharzia Risk Map

The risk mapping procedure using the snail sites, simulated snail habitat and the population distribution yields the figure above. The area generally is at a low to an average risk of bilharzia infection (Figure 27). The results accurately 


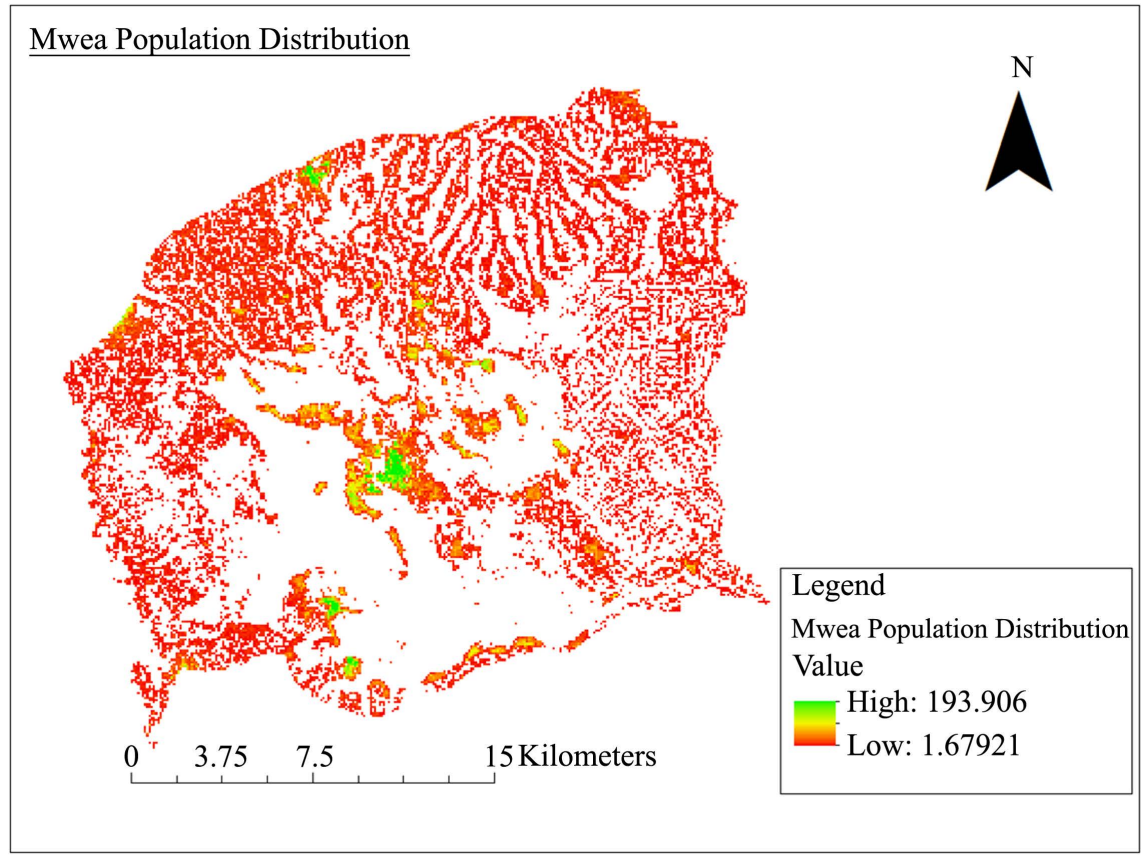

Figure 26. Population distribution map.

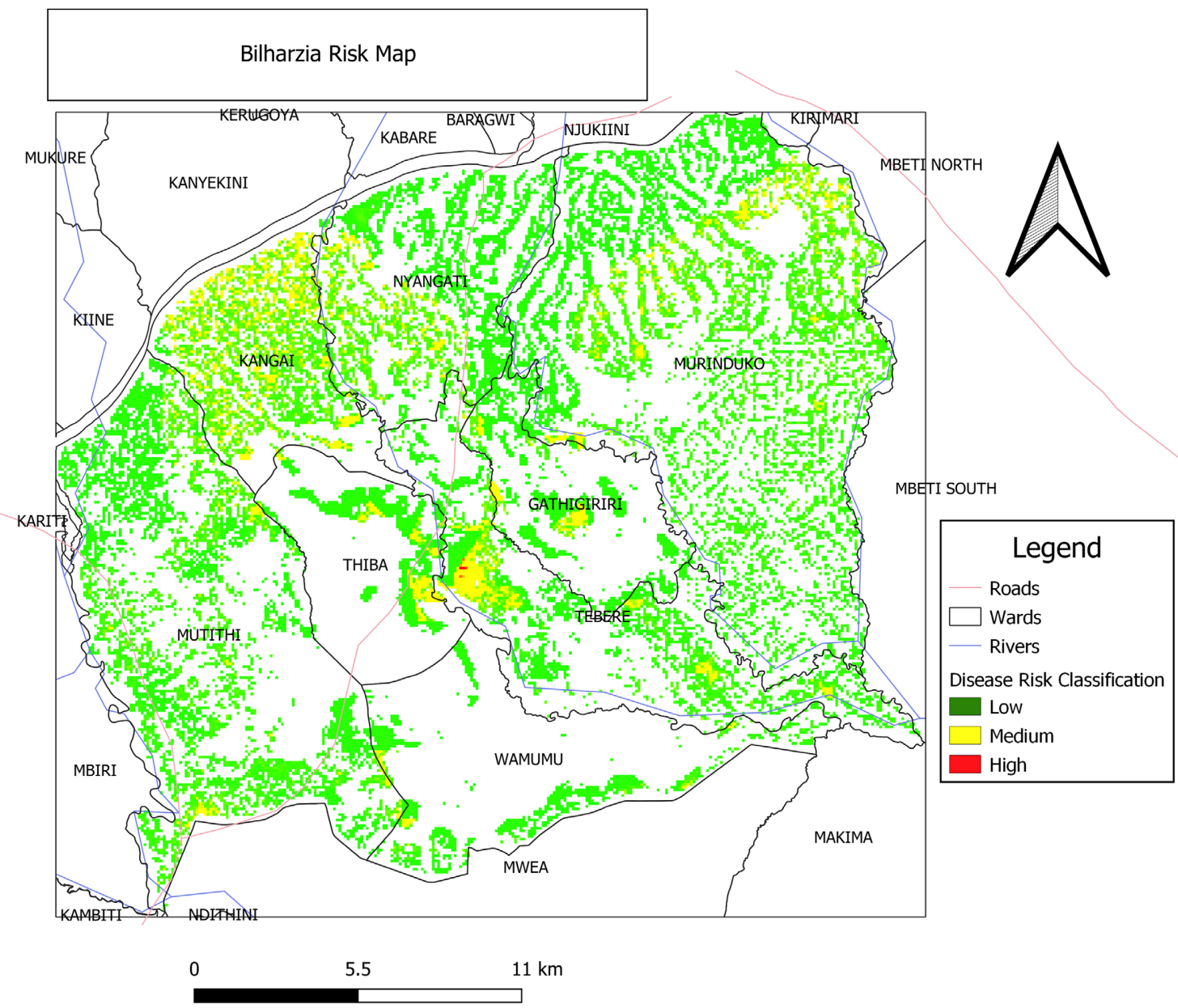

Figure 27. Bilharzia risk map. 
depict that the population very close to where there were simulated a high number of snail habitats also have the highest risk of bilharzia infection. The white parts are the simulated snail habitats as observed on the prediction maps.

\section{Conclusion}

The use of the Landsat 8 (OLI) imagery and the MaxEnt model has proven to be an effective way of modelling the conditions on the ground suitable for the survival of the snails. The extracted variables from this imagery can be used confidently to map freshwater snail habitats. The study of the variable conditions and the snail habitats indicates that the most probable snail habitats are the areas that the vegetation is really short but in wet lands (marshy areas), the crop lands (i.e. the paddy fields) and at the soil $\mathrm{pH}$ of around 3.5.

The flooded areas around Thiba, Teberre and Gathigiriri wards account for the most likely radius within which the freshwater snails spread during flooding or when there is a change in water levels. Mwea largely consists of clay soil and the montmorillonite clay type accounts for the flooded areas that are suitable for the snail survival.

Studying the elevation, flooding patterns and distribution of the snail habitats; one can conclude that Mwea is not the source-habitat of the snails but rather it falls as a radius area within which the snails have been dispersed from another region.

The population at large is not at a high risk of being infected by Bilharzia. Only the persons residing within the Gathigiriri ward and Teberre wards are at the highest risk. Thiba, Kangai and Murinduko wards fall at an average risk of infection.

The research recommends that further studies should be carried out on neighboring sub-counties as they are the obvious source habitats of the snails. The research shows that the snails are only in Mwea because they migrated there via the rivers and the irrigation systems.

\section{Acknowledgements}

We would like to thank the providers of the data and all that supported this project in providing relevant information for use during the analysis stages.

Our sincere appreciation goes to our departments (IGGReS) and to GEGIS department in particular for providing a conducive environment, support and equipment during this research period and mostly throughout the study.

\section{Conflicts of Interest}

The authors declare no conflicts of interest regarding the publication of this paper.

\section{References}

Brooker, S. (2002). Schistosomes, Snails and Satellites. Acta Tropica, 82, 207-214. 
https://doi.org/10.1016/S0001-706X(02)00012-8

Elith, J., Phillips, S. J., Hastie, T., Dudík, M., Chee, Y. E., \& Yates, C. J. (2011). A Statistical Explanation of MaxEnt for Ecologists. Diversity and Distributions, 17, 43-57. https://doi.org/10.1111/j.1472-4642.2010.00725.x

Li, Y., Zeng, L., Zhou, Y., Wang, T., \& Zhang, Y. (2014). Preparation and Characterization of Montmorillonite Intercalation Compounds with Quaternary Ammonium Surfactant: Adsorption Effect of Zearalenone. Journal of Nanomaterials, 2014, Article ID: 547139. https://doi.org/10.1155/2014/547139

Manyangadze, T., Chimbari, M. J., Gebreslasie, M., Ceccato, P., \& Mukaratirwa, S. (2016). Modelling the Spatial and Seasonal Distribution of Suitable Habitats of Schistosomiasis Intermediate Host Snails Using Maxent in Ndumo Area, KwaZulu-Natal Province, South Africa. Parasites \& Vectors, 9, Article No. 572. https://doi.org/10.1186/s13071-016-1834-5

Mitra, A. K., \& Mawson, A. R. (2017). Neglected Tropical Diseases: Epidemiology and Global Burden. Tropical Medicine and Infectious Disease, 2, 36. https://doi.org/10.3390/tropicalmed2030036

Pedersen, U. B., Stendel, M., Midzi, N., Mduluza, T., Soko, W., Stensgaard, A. S., \& Kristensen, T. K. (2014). Modelling Climate Change Impact on the Spatial Distribution of Fresh Water Snails Hosting Trematodes in Zimbabwe. Parasites \& Vectors, 7, Article No. 536. https://doi.org/10.1186/s13071-014-0536-0

Sanico, A., Peng, S., Laza, R., \& Visperas, R. (2002). Effect of Seedling Age and Seedling Number Per Hill on Snail Damage in Irrigated Rice. Crop Protection, 21, 137-143. https://doi.org/10.1016/S0261-2194(01)00075-8

Seto, E., Xu, B., Liang, S., Gong, P., Wu, W., Davis, G., \& Spear, R. (2002). The Use of Remote Sensing for Predictive Modeling of Schistosomiasis in China. Photogrammetric Engineering and Remote Sensing, 68, 167-174.

Shi, Y., Qiu, J., Li, R., Shen, Q., \& Huang, D. (2017). Identification of Potential High Risk Habitats within the Transmission Reach of Oncomelania Hupensis after Floods Based on SAR Techniques in a Plane Region in China. International Journal of Environmental Research and Public Health, 14, 986. https://doi.org/10.3390/ijerph14090986

Simarro, P., Cecchi, G., Franco, J., Paone, M., Diarra, A., Ruiz-Postigo, J., et al. (2012). Estimating and Mapping the Population at Risk of Sleeping Sickness. PLOS Neglected Tropical Diseases, 6, e1859. https://doi.org/10.1371/journal.pntd.0001859

Zhang, Z. Y., Xu, D. Z., Zhou, X. N., Yun, Z., \& Liu, S. J. (2005). Remote Sensing and Spatial Statistical Analysis to Predict the Distribution of Oncomelania Hupensis in the Marshlands of China. Acta Tropica, 96, 205-212.

https://doi.org/10.1016/j.actatropica.2005.07.027 